\section{Focus on psychiatry in Australia}

\author{
SCOTT HENDERSON
}

Humankind has been present on the Australian continent for at least 40000 , some say 60000 years, remarkably adapted to the environment and having a cultural tradition appreciated by few Caucasians. White people have been here for only 200 years; and psychiatry for about half of that. We know nothing about the mental health of pre-contact indigenous peoples; but we now know a little about the ways in which mental disorders are explained and treated by traditional methods. In two centuries, the Aboriginal and Torres Strait Islands communities, which are very diverse, have been steadily reduced to become only $1.5 \%$ of the population. From settlement in 1788 until the 1950s, most non-aboriginal Australians were of Anglo-Saxon or Celtic origin. Since the Second World War, the pattern of immigration has greatly enriched Australian life, first through large numbers of people from the Mediterranean littoral, Western Europe and the Balkans, and more recently from south-east Asia. Ethnic diversity is now evident in most peoples' daily lives - whom you see in the street, whom you work alongside, who your friends are, what you eat and who you have as patients. So the present Australian population of 18 million has undergone a marked change in demography and lifestyle within only two generations. Like the people, psychiatry is also changing rapidly. Where are the changes taking place? What is it like to be a psychiatrist here at present? Where has there been success and where has there been failure? Where is there lots of action?

\section{HEALTH SERVICES}

Australia is a federation of six states and two territories (the Northern Territory and the Australian Capital Territory). All public (general) hospitals and community services are managed by the states. Salaried specialists, including psychiatrists, working in these services are employed by the state health authorities. The Commonwealth Government provides health insurance for all Australians through Medicare, and also gives a subsidy to each of the states for health services. Nearly all general practitioners (GPs) are self-employed, like all specialists in private practice. Both GPs and specialists have $85 \%$ of the standard (scheduled) fees reimbursed to all patients by Medicare, for which there is a levy of about $2 \%$ on a person's income. Admission to a public hospital is free, but one can elect to be a private patient, or go to one of the private hospitals, some of which are excellent and may include undergraduate or postgraduate training. In general hospitals, some of the consultant staff are salaried specialists and others are in private practice but paid sessionally for their work. In each of the main capital cities, there are now a number of private psychiatric hospitals.

Since psychiatric services are now administered in the same way as other health services, each of the states and territories is responsible for the provision of mental health services within the public domain. Each state has its own Mental Health Act, and special arrangements have to be made to send a patient on a Community Treatment Order across a state border. It will inevitably mean an application to two tribunals. If I ask for a second opinion from a colleague in Melbourne for an in-patient in Canberra, he or she has to obtain medical registration in the Australian Capital Territory before examining the patient.

\section{THE WORKFORCE}

About $80 \%$ of the 2000 psychiatrists in Australia are in private practice, often working solo, sometimes in small groups sharing rooms. Over one-quarter are women. The other $20 \%$ are in salaried appointments with mental health authorities or in university medical schools. Only a tiny number are in research appointments. Andrews \& Hadzi-Pavlovic (1988) and Andrews (1989) have given a quantitative account of the work done by Australian psychiatrists, as revealed by self-report. The great majority of psychiatrists are Fellows of the Royal Australian and New Zealand College of Psychiatrists (RANZCP), for which the current training period is five years. Recruitment into psychiatry has increased from 61 new trainees in 1992 to 124 in 1998. Nationally, there are 652 trainees at present, of whom 300 are women. About 100 trainees pass the Fellowship Examination each year. It is a tough examination that now includes an assessment of how the candidate would perform in, say, a consultancy in a school or local community. Unlike Britain, the Fellowship is an exit examination because it licenses one to practise as a consultant from the next day, with no further period of supervision. Australian trainees in psychiatry are now much less likely to spend a period in Britain or America seeking advanced postgraduate experience. The College is gradually introducing a Maintenance of Practice Standards (MOPS) programme for all Fellows. This is voluntary at present, but may later become mandatory for recognition as a specialist.

As in other countries, the geographical distribution of psychiatrists is greatly to the disadvantage of the Australian public living outside the capital cities. A particular concern in recent years has been a marked increase in youth suicide, particularly in young rural men. Because of the great distances involved, rural and remote communities and many country towns do not have any access to a psychiatrist. This situation has become of much concern to administrators, consumers and clinicians. In many areas, it has led to the introduction of special arrangements, including telepsychiatry and more clinicians making visits to rural and remote areas.

\section{INCOMES}

A typical salary for a specialist psychiatrist in a hospital or area mental health service is around $\$ 140000$ per annum ( $£ 56000$ ). There is no merit award system and it is unlikely ever to be introduced. The top income tax rate in Australia is 48.5 cents in the dollar. Academic salaries are now well behind those for service appointments. For example, a senior lecturer has a salary of $\$ 81000$ 
( $£ 32400$ ), which includes a clinical loading. A professor's salary is about $\$ 103000$ $(£ 41200)$. Both salaried specialists and academic staff are allowed limited private practice, usually about a half-day a week. In full-time private practice, gross incomes start at about $\$ 200000(£ 80000)$. It is important to understand that, under the present funding arrangements, private psychiatrists generate an income only when they are with a patient, the only exceptions being for court appearances or the preparation of legal reports. The running costs of a practice are substantial. If private psychiatrists attend a conference, their income stops for that period. Patients can be seen by a psychiatrist in private practice only if referred by another medical practitioner, usually a GP. The fee set by the Commonwealth Department of Health for a consultation lasting $45-75$ minutes is $\$ 133$ $(£ 53.20)$ of which Medicare reimburses the patient $85 \%$.

\section{AUSTRALIA'S NATIONAL MENTAL HEALTH STR ATEGY}

After two centuries of $a d$ hoc arrangements for mental health services, the Ministers of Health in all the states and territories agreed in 1992 to a National Mental Health Strategy. This was articulated in three major documents: the Mental Health Statement of Rights and Responsibilities (Commonwealth Department of Community Services and Health, 1991); the National Mental Health Policy (Australian Health Ministers Conference, 1992a) and the National Mental Health Plan (Australian Health Ministers Conference, 1992b). The impetus for reform that the Strategy generated has been invaluable, a great deal of it owing to the helmsmanship of Harvey Whiteford, who did his job so well that the World Bank recruited him. The Strategy has brought about remarkable changes in the delivery of mental health services. Reliance on stand-alone psychiatric hospitals was reduced, there has been a large expansion in community-based care integrated with in-patient care, and mental health services have been fused wherever possible with other components of health care. By $1997,67 \%$ of acute psychiatric beds were in general hospitals, and there was a genuine redeployment of resources - financial and human - from the old psychiatric hospitals to general hospital units and community-based services. For the first time, consumers and carers began to participate in decision-making and advocacy. "Nothing about us without us" is their aphorism. This took place nationally, leading in 1998 to the formation of the Mental Health Council of Australia as the principal body representing consumers and carers, professions and non-governmental organisations. The Council has a powerful influence on governments and policy. It is currently pressing for an obligatory 'mental health impact assessment' for national or local initiatives, just as these are required for environmental impact.

Other initiatives in the National Mental Health Plan have been the improvement of information on mental health services, including measures of outcome. It has also been necessary to examine how health professionals are deployed in Australiawhom they deal with, and who may be conspicuously under-serviced. We know that there are marked gradients in service use between socio-economic groups. Jorm et al (1993) found a marked gradient in the use of private (Medicare-reimbursed) psychiatric services between the most affluent and the most deprived areas of Australia.

\section{Indigenous Australians}

Mental health services for much of the indigenous Aboriginal and Torres Strait population are often seriously deficient. There are very high rates for alcohol misuse, violence and suicide (Hunter, 1993). No good epidemiological data on mental disorders are available for two reasons: access for such research is usually refused by the people themselves, who have had enough $\mathrm{PhD}$ students inspect their lives with no benefit; and there are real problems in case ascertainment using Western methods. But some of the services are exemplary. In Alice Springs in the very centre of Australia, a recent initiative has been to appoint a carefully-selected but lucky senior registrar there for a year, with no responsibility for the people of Alice Springs. Instead, he or she is given a four-wheel drive vehicle and responsibility for a huge parish of the Aboriginal people (the Arrente, Pitjantjatjara, Warlpiri and Pintupi, to name the principal groups) spread across an area much greater than mainland Britain. Two years ago, I took two weeks off to be the locum psychiatrist at Alice Springs Hospital. It was immensely enjoyable, with only a light clinical load as it happened, but marvellous evening conversations with a psychiatrist/Jungian analyst and superb birdwatching, particularly finches. Then there was a five-hour drive to the Aboriginal community at Yuendumu to watch the registrar do his clinic and return to his family a young man who had recovered from a recurrence of his psychosis. As we drove to Yuendumu, the man explained to me what had gone wrong with his mind: a wedge-tailed eagle had come down on top of his head and scrambled his brains with its talons. I think a politically sensitive and sincere attempt is being made to develop appropriate services in the Outback. In Western Australia, Aleksander Janca (formerly of the World Health Organization, Geneva) has joined Assen Jablensky's University Department of Psychiatry to help develop rural and remote services in the Kimberley region - the far north-west visiting Broome and other remote communities regularly to develop and evaluate culturally appropriate interventions, but also to undertake some highly innovative research on nosology. For example, Janca is trying to develop culturally sensitive definitions such as 'fatal despair', and instruments to assess such states. Here is an example of mutually beneficial cooperation between a university and a state mental health service.

\section{Australia's National Survey of Mental Health and Well-Being}

To inform the National Mental Health Strategy, Gavin Andrews, Wayne Hall, Harvey Whiteford and I have collaborated to ensure that Australia now has its own National Survey of Mental Health and Well-Being. It has three parts: a survey of the general population, based on a sample of 10600 persons aged from 18 years to the most elderly (McLennan, 1998; Andrews et al, 1999; Henderson et al, 2000); a survey of children and adolescents; and a survey of the psychoses in four sites: Perth, Melbourne, Canberra and Brisbane (Jablensky et al, 1999). The Survey has already proved of great value scientifically and for advocacy.

\section{Second National Mental Health Plan}

The Second National Mental Health Plan (Commonwealth Department of Health and Family Services, 1998) is now under way using three key themes: promotion and prevention; partnerships in the reform of services; and determining how well services perform in terms of quality and consumer outcomes. To try to achieve these, 
there will be a major effort to improve the mental health literacy of the general population at all ages. In a nationally representative survey, Jorm et al (1997) found that the public like to take their psychological problems to GPs, they think psychiatrists are appropriate for schizophrenia but less so for depression and many think antidepressants are harmful. Baseline information of this type on beliefs and attitudes is valuable in guiding the national programme on mental health literacy.

A second task is far from new: to improve the recognition and management of mental disorders in primary care, particularly general practice. For Australia, that means finding out what would help GPs to improve their performance in recognising and treating common mental disorders and alcohol misuse. Medical schools and the pharmaceutical industry have worked very hard for at least 30 years at making GPs better in this area. Success has been modest. Some of us think that what will improve performance is not more postgraduate training alone, but also a change in the system of payment. At present, GPs can generate a reasonable net income $(£ 30000-40000)$ only if they see many patients a day. Patients who need a longer time spent with them are unprofitable. For most GPs, treatment of psychological problems is mainly pharmacological, and the selective serotonin reuptake inhibitors are costing the Commonwealth Government dearly. Big changes in general practice are envisioned.

\section{Community mental health services}

Although one hears the familiar criticism about money saved from mental hospitals never reaching community services, my distinct impression is that human resources for working with the severely disabled in the community are now generally very good, albeit only in urban Australia. For example, I was told recently by a community nurse during my ward round that one patient with psychosis could be visited three times daily if necessary after his discharge, including weekends, at least for a few weeks. A Japanese Visiting Fellow at our Centre remarked that in his country, such a patient might be visited annually by a public health nurse. Most Australian communities now have a mental health crisis team available at all times. But the shift to community care has brought many difficulties to light, just as in other countries. The workload for those in community teams is usually very high, and mainly deals with people with psychoses. The police shot a patient with psychosis in his flat because he presented a knife to them. There have been several such shootings in other states. Admittedly, this has led to the police receiving special training for their work with people with mental illnesses.

\section{SOURCES OF TENSION}

There is tension between clinicians and mental health tribunals when the latter begin to intrude on clinical decisions, such as treatability, or even choice of medication. I recently heard a magistrate from a mental health tribunal, who happened to look into a psychiatric ward after his sitting, say to a patient on a Treatment Order, "And how have you been since you started on risperidone? Do you find it better than the other drug?"' There are tensions between psychiatrists and the other health professionals. As in any conflict among higher primates, this is inevitably about dominance hierarchies, territory and scarce resources. Most unhappy of all are antipathies between medical and nursing staff, either in in-patient units or in community teams. I think registrars find this particularly discouraging, when they are themselves trying to learn new clinical skills in the management of disturbed behaviour.

For consultants, there has been a drift from salaried posts to private practice in recent years, driven in large part by the introduction of managers from industry, the public (civil) service or the non-medical health professions to senior appointments in regional health authorities. As elsewhere, many psychiatrists have found this a toxic experience and have given up in their attempts at conflict resolution, entering private practice. "What is a good doctor like you doing in a salaried job?" is not an uncommon question from other doctors or lay-people. This is antithetical to what applied when I last worked in Scotland, and yet it is becoming understandable, even to me.

\section{CLINICAL IDEOLOGIES}

Within Australian psychiatry, there are very few extremists now. Most Australian psychiatrists have a deep respect for competent history-taking and usually offer a healthy mix of psychotherapy and medication. Bear in mind, though, that such treatment is often obtainable only from private psychiatrists or academics, and for those who can afford to pay the amount charged above the Medicare rebate. The psychotherapy is rarely long-term. For patients reaching psychiatrists, the average number of visits per year is 7.2. Psychological treatments are directed at current problems rather than achieving psychodynamic insights. This is not a trivial matter to bear in mind when it comes to considering how a country's human resources, trained at great expense, are deployed against mental disorders. After all, psychodynamic therapy is offered for Alzheimer's disease in some countries of Western Europe. Among the psychiatrists I meet across Australia, there is general agreement about the following.

(a) Private and public psychiatrists are isolated from each other in their clinical work and, for many, in their professional ideology. But they do come together at College meetings, grand rounds or drug company dinners.

(b) For patients with severe disablement and little insight, private psychiatrists are unlikely to initiate a home visit or consultation. Some say they might be seen to be 'over-servicing', thereby risking censure by the Health Insurance Commission, which runs Medicare.

(c) Under present conditions, private psychiatrists see patients who want to be seen and who will turn up for appointments. This is quite different from the service users of salaried psychiatrists.

(d) Private psychiatrists already have full case loads and are booked for many months in advance. They would therefore have to reduce their established service users and their network of referring GPs if they were to start taking people currently treated by public mental health services.

(e) Where private psychiatrists engage in 'shared care' with a GP, there is usually good continuity. The psychiatrists say this is unlike their experience with non-medical case managers from state mental health services, who themselves have high turnover and are often not to be found when needed.

(f) Private psychiatrists ask: how effective are the personnel presently employed in state mental health authorities? One psychiatrist now in private practice said he had commonly met clinical psychologists who would not see more than six patients a day. Why would they want to do more work? 
(g) Private psychiatrists would like State and Commonwealth Ministers of Health and senior administrators to stop making denigrating but unfounded remarks about them. They do not see many 'worried well' people in truth. Yet that myth is resolutely held by many salaried psychiatrists, academics and administrators. Everyone should understand that psychoses are only one cause of serious disablement, family distress, reduced productivity and absenteeism. Private psychiatrists are dealing, inter alia, with large numbers of people who are markedly disabled in daily life by their symptoms.

(h) A complaint from public psychiatrists is that many Australians do not have access to private psychiatric care because they cannot afford it. They could not manage to pay the gap between $85 \%$ of the scheduled fee, which is paid by Medicare, and the total fee charged for the consultation. Yet private practice is where some $80 \%$ of our psychiatrists are working. Social equity is a concern, but only to some.

\section{THE ROYAL AUSTRALIAN AND NEW ZEALAND COLLEGE OF PSYCHIATRISTS}

The College began in 1964, arising out of the Australasian Association of Psychiatrists and gaining its Royal Charter in 1978. We do not know what will happen to the Royal adjective if Australia and perhaps later New Zealand become republics. A valuable history of the College is entitled, Menders of the Mind (Rubinstein \& Rubinstein, 1996). To me, the RANZCP differs greatly from its British counterpart in its function and in the issues that it takes on as important. It has to act as a trade union, a scientific body and as a professional council for both private and salaried psychiatrists, doing so in two countries with different types of health service. In this, its relationship with the Australian and New Zealand Governments is likely to be influenced by two opposing forces: the one, to behave with the scientific competence expected of a Royal College; and the other, to protect its members from having their way of practising psychiatry altered inappropriately. Despite the range of its responsibilities, the College has enabled a lively group of sub-specialities to develop: the Faculty of Child and Adolescent Psychiatry; the Sections on Alcohol and Other Drugs; Consultation-Liaison Psychiatry; Forensic Psychiatry; the Psychiatry of Old Age; and the Section of Psychotherapy.

\section{RESEARCH IN AUSTRALIA}

It is remarkable how research has flourished in Australia within only four decades. When I arrived in Sydney in 1963 to become Leslie Kiloh's first registrar, there was little research in progress nationally. In Melbourne, John Cade (1949) had drawn attention to the mood-stabilising effect of lithium, but the rest of the world was only starting to look at it. In Sydney, David Maddison was interested in bereavement. In Adelaide, my fellow Aberdonian, William Cramond, had begun studies of people who were facing death from renal failure. In 1999, there are over 20 Professors of Psychiatry in what are, without exception, energetic and scientifically productive university departments. The Australian (now Australasian) Society for Psychiatric Research (ASPR) has burgeoned for over 20 years and now has over 150 members. It meets annually for three days in one of the capital cities, preference being given to younger investigators seeking critical assessment of their work. Significantly, over half of the members are not psychiatrists but come from other relevant areas of science. In this way, the ASPR fulfils a function that cannot be met by the RANZCP. Much of the idea for the ASPR was based on Cecil Kidd's and my own experience of the equivalent Scottish Society in the early 1960s. Proportionate to the denominator in other countries, Australian authors now contribute significantly to the best journals. Areas in which particular contributions have been made, sometimes outstandingly, include the following:

(a) the phenomenology and treatment of both the depressive and the anxiety disorders;

(b) abnormal illness behaviour and somatisation disorder;

(c) the prevention of mental disorders and the promotion of mental health;

(d) the epidemiology of the common mental disorders and the social environment;

(e) the epidemiology of mental disorders in late life; (f) the epidemiology and neurobiology of schizophrenia;

(g) early intervention in the psychoses;

(h) health service research;

(i) mental health problems and services for indigenous Australians;

(j) alcohol and drug misuse;

(k) post-traumatic stress disorder; and

(l) psychiatry and ethics.

\section{KEEPING THE BALANCE IN RESEARCH}

So far, we have kept a balance between research on clinically fundamental issues such as aetiology and the course of disorders, and research on health services and health economics. The latter has regrettably come to play a dominant part in the contemporary research agenda in both Australia and Britain. It is something to be careful about lest it take up all the attention of our best minds. Among colleagues across the continent of Australia, there are still some who are interested in ideas about clinical psychiatry, and in the construction of scientific environments where ideas themselves are a valued product. The National Health and Medical Research Council (NHMRC) has funded our own Centre for nearly 25 years. No-one has tenure. We have been rigorously reviewed every four years, so far successfully. To its great credit, the NHMRC has never tried to influence the direction of our research. Anything resembling health services research would meet its approval only if there were good science in the study as well. Health services research is for the Commonwealth and State Departments of Health. And then, in 1998, something unusual happened. The Federal Government set up a Health and Medical Research Strategic Review under the chairmanship of Peter Wills, an industrialist and chair of the board of the prestigious Garvan Institute of Medical Research in Sydney. One outcome of this is that the Government has greatly increased its funding for the NHMRC over the next six years, effectively doubling it by 2005 (Finkel, 1999). Although psychiatry, like other clinical disciplines, has always done rather poorly in project grants compared to wet-lab research, this is a great boost to our hopes. We also know that a doubling of research funding is unlike the experience of many other countries at this time. 


\section{INVOLVEMENT WITH THE REST OF THE WORLD}

Australian psychiatrists as a whole travel extensively, despite the costs. A large number go to the American Psychiatric Association conference every year. A much smaller number go to the British College's Annual Meeting. For some, meetings in China, Malaysia, Thailand, Indonesia, Vietnam and Oceania (the small south Pacific nations) are seen as important because it is felt that a contribution can be made in such countries to training and the development of services. Furthermore, the multiethnic demography of Australia is such that it is good to have connections with the parent countries of many of our citizens. To these ends, some universities and state mental health authorities have established transcultural psychiatry centres for research, training and services.

My impression is that Britain has become a less popular destination for advanced educational or research travel. The USA and Canada are seen by most as a preferred destination. On visiting the main postgraduate centres in England, some Australians have been disappointed both professionally and personally in their reception, unless they had previously established contacts. As hosts in the future, Australians hope that receiving guests from England, and elsewhere in the UK, will continue to be bilaterally valued. What is quite unwelcome is someone who is brought here as a guest, all expenses paid, but presents material that most have previously read in the main journals!
Australian psychiatry is in excellent shape. Sure, there are problems. But there is also much goodwill and a pervasive effort to be flexible. I think Australia's greatest asset in psychiatry is its community of clinical scientists. Personally, Australia has allowed me to carry out epidemiological research without administrative interference for over 25 years. I would happily take another 25 .

\section{ACKNOWLEDGEMENTS}

I much appreciate criticism of an earlier draft from colleagues at my Centre and further afield.

\section{REFERENCES}

Andrews, G. (1989) Private and public psychiatry: a comparison of two health care systems. American Journal of Psychiatry, 146, 881-886.

_ \& Hadzi-Pavlovic, D. (1988) The work of Australian psychiatrists, circa 1986. Australian and New Zealand Journal of Psychiatry, 22, 153-165.

_ , Hall, W., Teeson, M., et al (1999) The Mental Health of Australians. Canberra: Commonwealth Department of Health and Aged Care.

Australian Health Ministers Conference (1992a) National Mental Health Policy. National Mental Health Strategy, Commonwealth Department of Health, Housing and Community Services. Canberra: Australian

Government Publishing Service.

- (1992b) National Mental Health Plan. National Mental Health Strategy, Commonwealth Department of Health, Housing and Community Services. Canberra: Australian Government Publishing Service.

Cade, J. F. J. (1949) Lithium salts in the treatment of psychotic excitement. Medical Journal of Australia, 2, 349-352.

Commonwealth Department of Community Services and Health (1991) Mental Health Statement of Rights and Responsibilities. National Mental Health
Strategy, Commonwealth Department of Community Services and Health. Canberra: Australian Government Publishing Service.

Commonwealth Department of Health and Family Services (1998) Second National Mental Health Plan National Mental Health Strategy, Commonwealth Department of Health and Family Services. Canberra: Australian Government Publishing Service.

Finkel, E. (1999) Budget backs report on boosting biotech. Science, 284, 1248-1249.

Henderson, S., Andrews, G. \& Hall, W. (2000) Australia's National Survey of Mental Health and Well-Being. Australian and New Zealand Journal of Psychiatry, in press.

Hunter, E. M. (1993) Aboriginal Health and History: Power and Prejudice in Remote Australia. Cambridge: Cambridge University Press.

Jablensky, A., McGrath, J., Herrman, H., et al (1999) People Living with Psychotic IIIness: An Australian Study, 1997-98. Canberra: Commonwealth Department of Health and Aged Care.

Jorm, A. F., Rosenman, S. J. \& Jacomb, P. A. (1993) Inequalities in the regional distribution of private psychiatric services provided under Medicare. Australian and New Zealand Journal of Psychiatry, 27, 630-637.

_ , Korten, A. E., Jacomb, P. A., et al (1997)

Mental health literacy: a survey of the public's ability to recognise mental disorders and their beliefs about the effectiveness of treatment. Medical Journal of Australia 166, 182-186.

McLennan, W. (1998) Mental Health and Well-Being: Profile of Adults, Australia 1997. Canberra: Australian Bureau of Statistics, Australian Government Publishing Service.

Rubinstein, W. D. \& Rubinstein, H. L. (1996) Menders of the Mind. Melbourne: Oxford University Press.

Scott Henderson Director, National Health and Medical Research Council, Psychiatric Epidemiology Research Centre, The Australian National University, Canberra ACT 0200, Australia 